\title{
Analysis of Design and Technological Processes of Hot Recycling Asphalt Mixture at Batch Asphalt Mixing Plants
}

\author{
Mindaugas Martišius*, Henrikas Sivilevičius \\ Transport Engineering Faculty, Vilnius Gediminas Technical University, Vilnius, Lithuania
}

Received 05 February 2020; accepted 31 March 2020

\begin{abstract}
European Union members seek to establish the principles of a circular economy, which is based on the efficient use of raw materials and resources. This requirement will have an impact on business and in particular on the road construction sector. Hence the need to improve the asphalt mixing plant (AMP) mixing technology utilizing as much as possible reclaimed asphalt pavement (RAP) to produce asphalt mixtures (AM) for road construction. The resources used to produce new AM in the world are endless and becoming more expensive in a time scale. The multicycle reuse of RAP producing AM is a priority, when thinking about of economical recycling materials usage and the saving of resources. The design and development of RAP hot recycling in-plant technologies has been in progress for approximately half a century. In high-level-economy countries, AM production currently processes on average approx. $80 \%$ of the amount of RAP using innovative techniques on AMPs. Design of various AMP, their assessment on the flexible application of innovative techniques depending on the RAP processing method, are described in this paper. In this paper different recycling technologies in AMP and their advantages and disadvantages are reviewed. The research result indicates technical possibilities hot recycling in-plant in Baltic countries. Local authorities, research institutes, road construction and road design companies could use these results in the future.
\end{abstract}

Keywords: asphalt mixing plant (AMP), asphalt mixture, recycling, technological process.

\section{Introduction}

In recent years more and more recycled asphalt road pavements are gaining their new life, influenced not only on economical, but also as environmental background. Recycled asphalt pavement (RAP) materials are recyclable cold or hot, in-situ or in-plant, adding them into asphalt mixtures (AM) or mixing with aggregates for road subbase layers. This paper reviews RAP recycling possibilities at batch type asphalt mixing plants (AMPs) and most used RAP recycling in-plant method used in Baltic countries application theoretical and practical research.

AM is a complex product used to build road pavements. During production process of AM in AMP, virgin resources as aggregates, binder, filler, additives are used. RAP is an additional component which reduces production costs of AM mostly on virgin materials and binder costs. Indeed, the use of reclaimed materials is associated with a reduced demand for virgin non-renewable materials such as bitumen and mineral aggregates (Puccini et al., 2019). Optimization of the producing AM process mixing RAP and virgin materials is necessary in order to ensure correct homogeneity (Vislavičius \& Sivilevičius, 2013). In recent years the industry focus has been placed on increasing the amount of RAP in AM production. This is a result of tripled binder costs during the last decade that come at a time of extremely strained funding for road construction and maintenance (Zaumanis et al., 2014).

Nowadays the main world economies took course and tools to reduce $\mathrm{CO}_{2}$ path and save their resources and strongly pushes industry to reuse RAP at the highest possible level. Biggest European economy Germany is using early in average $10500000 \mathrm{t}$ of RAP producing approx. $4000000 \mathrm{t}$ of asphalt annually and it came to $26.1 \%$ proportion of RAP reuse in 2018 (Deutscher Asphaltverband, 2020). While in Lithuania, there is used only approx. 5\% of RAP producing new AM (Martišius, 2020). Depending on RAP quality, moisture, ambient conditions and AMP design average added RAP content to AM is $20 \%$.

The objective of paper by Shirodkar et al. (2011) is to provide a methodology to determining the degree of partial blending in high RAP mixtures. When RAP is mixed with virgin aggregates and virgin binder, partial blending of RAP binder occurs in the hot mix asphalt. Agencies limit the amount of RAP because the degree of blending between RAP and the virgin materials is not known. The result indicates with short mixing time, RAP tends to work as inert black rock and the complete blending situation only approached if the mixing duration significantly increased (Nguyen,

${ }^{*}$ Corresponding author. E-mail: mindaugas.martisius@vgtu.lt

\section{Copyright (C) 2020 The Author(s). Published by VGTU Press}

This is an Open Access article distributed under the terms of the Creative Commons Attribution License (http://creativecommons.org/licenses/by/4.0/), which permits unrestricted use, distribution, and reproduction in any medium, provided the original author and source are credited. 
2013). However, longer RAP/virgin aggregate mixing times could result in recycled hot asphalt mixtures with higher stiffness modulus and better homogeneity (Nguyen, 2013). Theoretical formulas which were used in this paper to calculate initial virgin materials temperature which is needed to heat RAP do not contain any variables which determine time. Results show that time must be considered for proper virgin materials temperatures determination. Zhang et al. had synthetically reviewed the fundamental thermodynamics and kinematics involved in the plant production of RAP mixtures and the corresponding numerical methodologies to quantify the thermal processes (Zhang et al., 2019). The review results from the experimental studies highlighted the importance of mixing time, mixture discharge temperature and silo storage time on the mechanical performances of laboratory-produced and plant-produced RAP mixtures.

Producing RAP mixtures, binder partly is substituted by fresh bitumen or rejuvenator. Rejuvenator is an oil that can be added during asphalt production to restore RAP binder. Ten potential locations for rejuvenator addition in asphalt plant were ranked in terms of pavement performance, plant operation and environmental safety. A full-scale production was performed to compare rejuvenator addition to cold RAP on conveyor belt versus addition to hot RAP in mixer (Zaumanis et al., 2019). As well it was evaluated the effects of rejuvenators addition to cold RAP before the RAP heating drum as opposed to the more conventional approach to add rejuvenator to hot RAP (Zaumanis et al., 2020).

A certain amount of volatile organic compounds (VOC) is emitted while RAP is recycled in-plant. Formation of VOC is leaded out of bitumen temperature increase and vaporing during this process. While VOC are odors and humans could simply identify them, $\mathrm{CO}, \mathrm{NO}_{\mathrm{x}}$ and other chemical compounds as well as dust are measured and regulated by authorities accordingly. Plant emissions restrictions are one of new challenges for AMP manufacturers. Difficulties with production technology have been reported, including excessive emissions (Mogawer et al., 2012).

\section{Design and technological processes}

The structural design of AMP is linear dependant on AM production process flow. In recent years, innovations are coming from structural design calculation and process flow combined with production control systems software optimization. In most cases, new commissioned AMPs already have integrated some kind of RAP recycling system. On the other hand, the design of almost every standard batch type AMP allows to retrofit it for RAP recycling afterwards. Same appears if AMP owner makes decision to turn from one RAP in-plant recycling method to another or make them combined. Additional equipment such RAP dosing hopper, conveyors or elevators, scales, RAP drying drum and other components not limited to control system and software needed to be incorporated and/or modified on existing AMP.

The asphalt mixing technological processes are unchanged for many decades. The manufactured AM with added RAP must meet the same technical requirements as those for the AM made of new materials only (Sivilevičius \& Vislavičius, 2019). There are several cold, hot and combined (cold/hot) recycling in-plant systems depending on added RAP content are shown in Table 1.

Table 1. RAP recycling in-plant methods overview

\begin{tabular}{|l|l|c|c|}
\hline \multicolumn{1}{|c|}{$\begin{array}{c}\text { RAP recyclingin- } \\
\text { plant }\end{array}$} & \multicolumn{1}{|c|}{ Method } & $\begin{array}{c}\text { Possible quantity RAP } \\
\text { to recycle in } \%\end{array}$ & $\begin{array}{c}\text { Required virgin aggregate } \\
\text { temperature in }{ }^{\circ} \mathrm{C}\end{array}$ \\
\hline $\begin{array}{l}\text { Cold RAP addition } \\
\text { (ambient } \\
\text { temperature) }\end{array}$ & Drum middle ring & from 25 to 40 & 160 \\
\cline { 2 - 4 } & Into hot elevator (hot bin bypass) & from 25 to 40 & Superheated up to 300 \\
\cline { 2 - 3 } & Into the mixer & from 25 to 40 & Superheated from 220 to 250 \\
\hline Hot RAP addition & Parallel drum & from 60 to 80 & 160 \\
\cline { 2 - 4 } & Counter-flow with indirect heating & from 80 to more than 90 & Superheated from 220 to 300 \\
\hline $\begin{array}{l}\text { Combined RAP } \\
\text { addition (cold/hot) }\end{array}$ & $\begin{array}{l}\text { Cold addition into the mixer + parallel } \\
\text { drum }\end{array}$ & from 40 to 70 & \\
\hline
\end{tabular}

Short overview of total number AMPs and AMPs where possible RAP different recycling methods in-plant in Baltic countries is given in Figure 1, where clearly stated that mostly AMPs are prepared for cold RAP addition method.

Taking into account requirements of authorities for RAP residual binder quality and gradation and method how RAP is added, influence of AMP control system design and algorithms should not ignored. This leads to in-time RAP dosing optimisation such as dynamic AM recipe adjustment during RAP feed. No matter how high RAP quality is if could be not be possible to add above listed RAP percentage because of the disadvantages of these methods (Gencer et al., 2012):

1. High temperature deteriorates quality of bitumen. RAP is exposed to direct temperature of $650-750{ }^{\circ} \mathrm{C}$ in a parallel dryer or asphalt plant dryer to dry RAP and bring the temperature min. $100-130{ }^{\circ} \mathrm{C}$. As a result, the quality of the bitumen in the RAP becomes worse. 
2. Exhaust gas emissions $\left(\mathrm{CO}, \mathrm{SO}_{2}, \mathrm{NO}_{\mathrm{x}}, \mathrm{VOC}\right.$, total organic carbon (TOC), polycyclic aromatic hydrocarbon (PAH), etc.) exceed the regulated by standards limits during heating and drying of the RAP in the AMP or parallel drum by exposing it to the temperature of $650-750{ }^{\circ} \mathrm{C}$.

3. AMP operation and maintenance difficulties with the increased stickiness of the RAP. Due to the bitumen and fine particles content in the RAP it becomes sticky while temperature of the RAP increases in the AMP parallel drum. Especially fine RAP particles are sticking on the drum lifters and decrease the efficiency.

4. Necessity of using more additives (anti-aging agents, rejuvenators, etc.). Additives improve weakened quality of the RAP due to the aging of the bitumen of RAP.

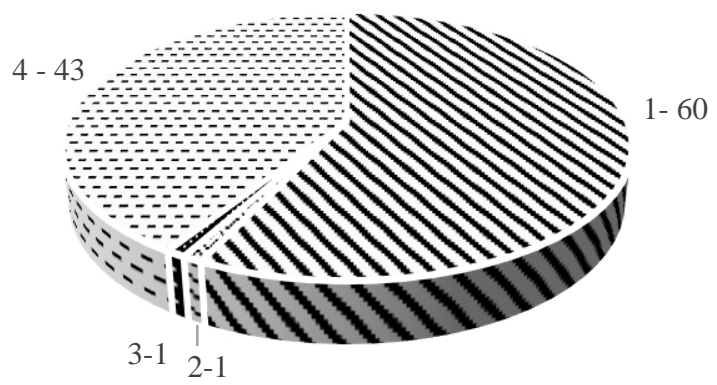

Figure 1. Diagram of AMP prepared for RAP recycling in Baltics. 1-60: 60 AMPs with cold RAP addition;

2-1: 1 AMP with hot RAP addition; 3-1: 1 AMP with combined RAP addition; 4-43: 43 AMP's without any RAP addition

\section{Cold RAP addition method}

Cold RAP addition is mostly used in Lithuania and this method is applied on 96\% of AMP prepared for RAP recycling. Figures $2 \mathrm{a}, 2 \mathrm{~b}$ and $2 \mathrm{c}$ show AMP and RAP dosing equipment installation design layouts for cold RAP addition application. Applying cold RAP addition method up to $40 \%$ of RAP is possible to add.

During cold recycling application RAP material is heated by mean of conduction when virgin aggregates are heating RAP in direct contact of particles and in drum middle ring case (Figure 2a) heat partly is transferred to RAP by mean of convection. This process limits maximum possible RAP portion to be added as there is insufficient quantity of mass of superheated aggregates.

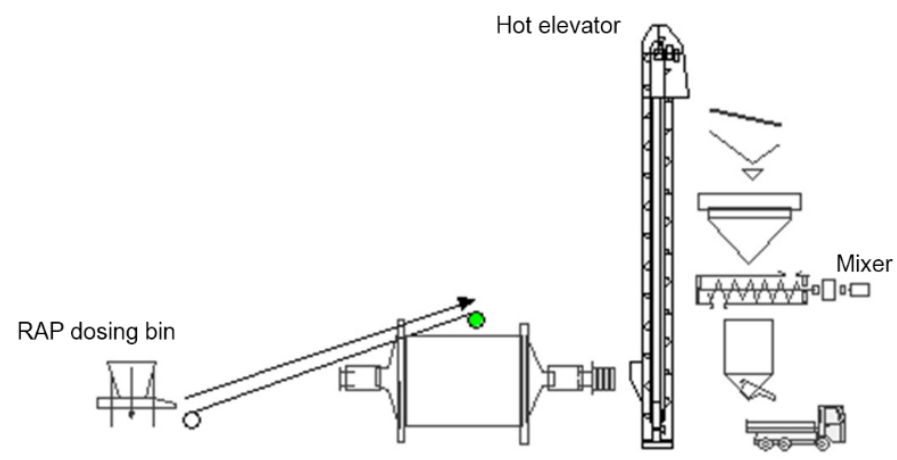

a)

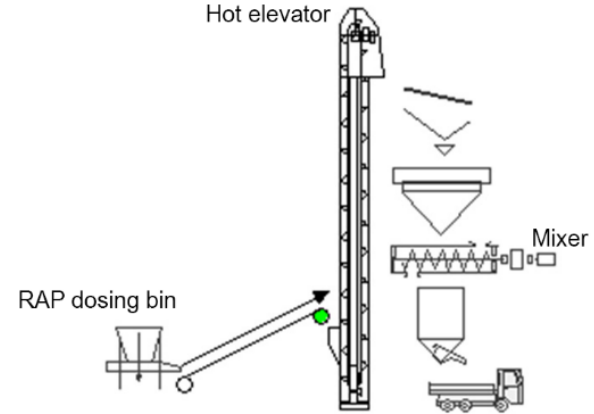

b)

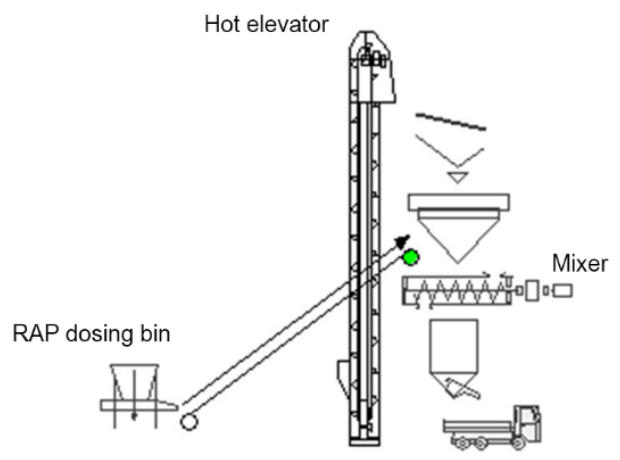

c)

Figure 2. Cold RAP addition: a) through drum middle ring; b) into hot elevator; c) into the mixer 
In case of drum middle ring (Figure 2a) and into hot elevator (Figure 2b), RAP particles are added into the AM production process before mixing phase and heated in hot aggregates bins. Positive effect is that heat to RAP is transferred gently and continuously making less negative impact on bitumen and minimizing its damages. During addition into the middle ring, the residual RAP moisture is vaporized and extracted through bag filter house. In case when RAP was stored in open areas and has high moisture content, possible to recycle RAP quantity is limited by filter house capacity. Other inconvenience of this method is limited screen usage as bitumen clogs screen cloth meshes reducing effective screening surface.

While RAP is added into mixer (Figure 2c) it appears in AM exact in mixing phase. Again, as it is described above, maximum possible to use RAP portion is restricted mostly by moisture content. Diameter of water vapor and dust routing pipe from mixer to bag filter house is limiting maximum RAP moisture amount. There are several possibilities to reduce negative effects in the market. Precise RAP weighing, exact controlled dosing, gentle addition prevents vapor shocks during water expansion same leading smooth continuous material heating in the mixer and increasing AMP components lifetime.

\section{Hot RAP addition method}

The highest RAP dosing portions to new produced AM quantities could be achieved during hot RAP addition in-plant method. Due to poor RAP quality there are not so many possibilities for applying this method in Lithuania. Figures 3a, $3 \mathrm{~b}$ and $3 \mathrm{c}$ show AMP and RAP dosing equipment installation design layouts for hot RAP addition application.

During hot RAP recycling in-plant, RAP is heated by convective heat transfer in parallel drum or heated indirectly in counter-flow. Parallel drum technology (Figure 3a) is proven technology worldwide over decades by many AMP manufacturers. Parallel drum is equipped with special designed burner. While virgin material in heating drum flows against burner fire, RAP in parallel drum is heated preventing direct flame contact and flows in burner flame (heat) direction. RAP and flame contact preventing is critical point because of the fact that damages on RAP bitumen has to be minimized or avoided. The RAP is heated up to $130{ }^{\circ} \mathrm{C}$ and later is dosed into mixer together with virgin material which also is superheated. Using RAP priority dosing option (Figure $3 b$ ) up to $80 \%$ RAP could be added. This method

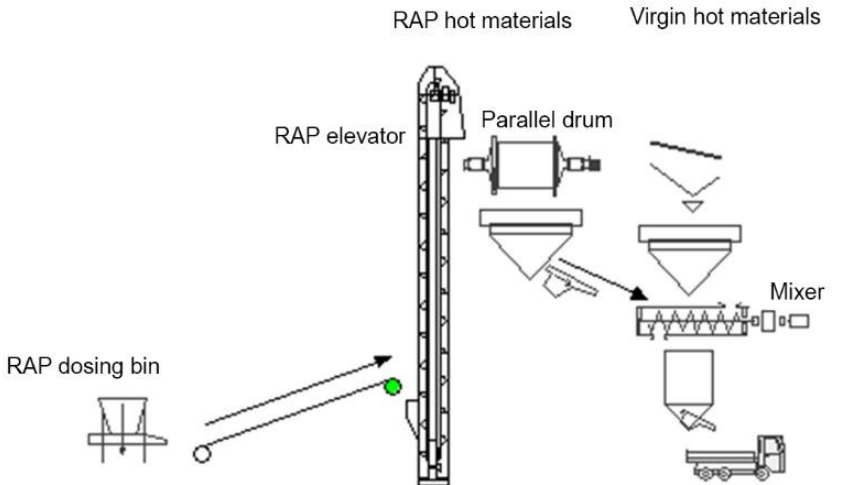

a)

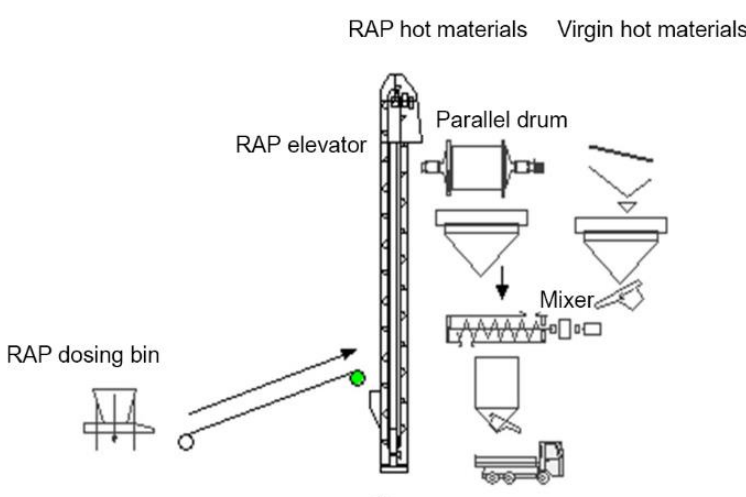

b)

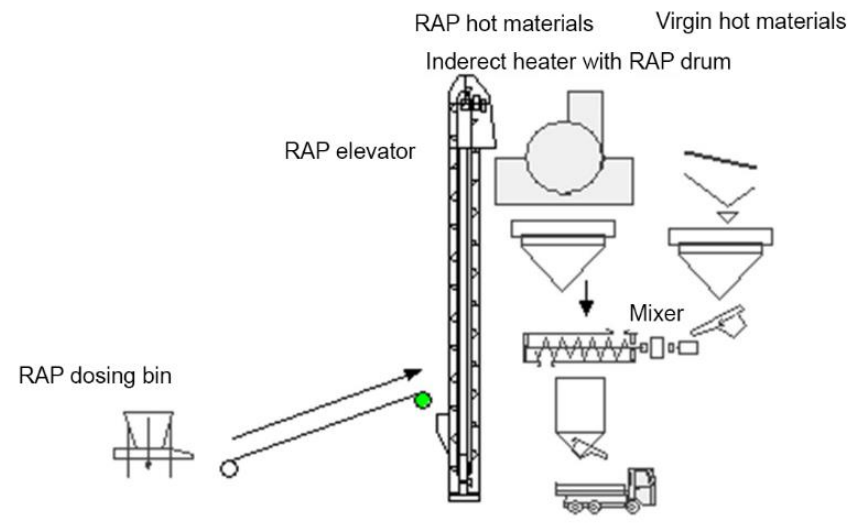

c)

Figure 3. Hot RAP addition: a) through parallel drum; b) through parallel drum, priority dosing; c) counter-flow with indirect heating method 
requires highest energy amounts as 2 drying drums are operated simultaneously on AMP. Most challenged management during this process is VOCs and other emissions control. The most important role is played by exhaust and filtering system configuration and control. Adding RAP too fine graded the fine particles are sticking on drum's lifters and making their operation inefficient.

Indirect RAP material heating (Figure 3c) lowers emissions, distributes heat more homogenous and reduces total required energy for AMP operation. This is the third hot RAP addition method called counter-flow with indirect heating. Today only three batch type AMP European manufacturers presenting such systems. Recycled material is heated to optimal technological temperature of $160{ }^{\circ} \mathrm{C}$ in a gentle way and not burning the bitumen. As emission requirements getting stricter parallel drum method could not comply with them in the future as counter-flow with indirect heating method would easily reduce emissions. Exhaust gas temperature from parallel drum is near $160{ }^{\circ} \mathrm{C}$ while from indirect heating drum approx. $100^{\circ} \mathrm{C}$. Use of this system means that emissions are lower, and AMP is more environmentally friendly. This method allows increase RAP quantity up to more than $90 \%$ depending on quality.

\section{Combined RAP addition method}

Combined RAP addition method is a mix of cold and hot RAP recycling in-plant. This method is most flexible as systems are used together or could be used separately according to the RAP addition quantities (small - cold addition, large - using parallel drum). Figure 4 shows AMP and RAP dosing equipment installation design layouts for combined RAP addition application.

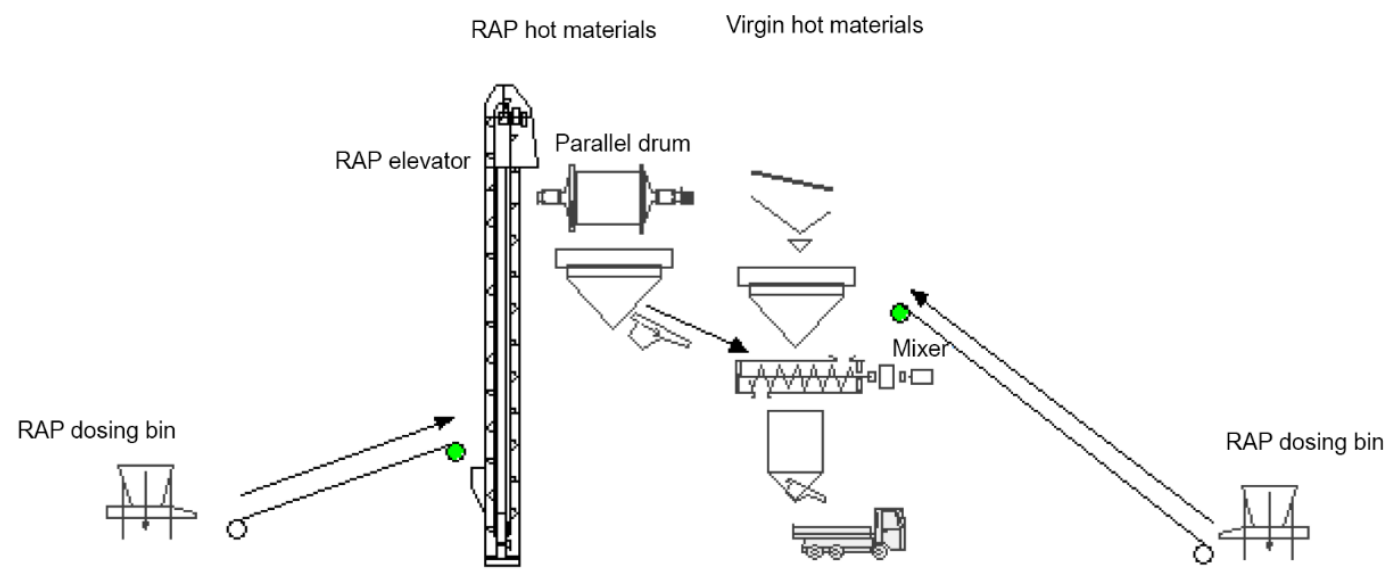

Figure 4. Combined (cold/hot) RAP addition scheme: partly into the mixer, partly parallel drum

This method's technological advantage is preventing fine particles sticking on parallel drum lifters if RAP fine fractions (for example, 0-8 mm) are added through mixer and RAP course fractions (for example, 8-22 mm) diverted to parallel drum.

\section{Experimental AM production test in AMP applying cold RAP addition method into the mixer}

Calculations were based under experiment conditions which was done at AMP with cold RAP addition into the mixer application attempting to study required superheated virgin materials temperature. Experiment took place in Northern Lithuania at December 2019 at the asphalt batching plant with $2 \mathrm{t}$ capacity mixer. For this experiment aggregates heating target was to heat up to $260{ }^{\circ} \mathrm{C}$ according AMP operator and authors professional experience and followed up by various recommendations sources to achieve targeted AM temperature of $160^{\circ} \mathrm{C}$. AM for road subbase AC32PS (Lithuanian Road Administration, 2009) was produced in amount of $64 \mathrm{t}$ in 33 batches adding 20\% of RAP. Virgin aggregates average measured on discharge from drying drum temperature was $257^{\circ} \mathrm{C}$. Mixing time from standard 45 $\mathrm{s}$ was increased to $95 \mathrm{~s}$. Conductive heat transfer process in order to heat RAP took place in mixer which was walls are additionally heated. Experimental data (this data was as reference for calculations) are provided in Table 2.

Table 2. Some main data of experiment at AMP

\begin{tabular}{|c|c|c|c|c|}
\hline $\begin{array}{c}\text { RAP quantity in } \\
\text { AM, } \%\end{array}$ & $\begin{array}{c}\text { RAP moisture } \\
\text { content, } \%\end{array}$ & $\begin{array}{c}\text { RAP temperature, } \\
{ }^{\circ} \mathrm{C}\end{array}$ & $\begin{array}{c}\text { AM targeted temperature, } \\
{ }^{\circ} \mathrm{C}\end{array}$ & $\begin{array}{c}\text { Virgin aggregates heating } \\
\text { temperature, }{ }^{\circ} \mathrm{C}\end{array}$ \\
\hline 20 & 4.8 & 5.3 & 160 & 257 \\
\hline
\end{tabular}


Different formulas were selected trying to figure out which parameter is critical. Formula (1) takes into account RAP quantity, temperature and moisture content, but does not underestimate AM temperature. Formulas (2) and (3) considers AM temperature, RAP temperature and quantity, but no entries of RAP moisture. In formula (4) AM temperature, RAP quantity and moisture are evaluated, but RAP temperature - not. All formulas do not contain any information about possible mixing and blending time between virgin aggregates and RAP which could be critical variable especially in cold RAP addition.

Required virgin aggregates temperature $T_{V A}$ which is needed to achieve targeted AM temperature of $160{ }^{\circ} \mathrm{C}$ were calculated in different way according to formulas (1), (2), (3) and (4):

(1) (Sivilevičius et al., 2017):

$$
T_{V A}=\frac{\mathrm{T}_{R A P}-S_{R A P} \cdot T_{R A P}}{1-S_{R A P}}+\frac{4 \cdot S \cdot W_{R A P}}{1-S_{R A P}}\left(637-T_{R A P}\right),
$$

where: $T_{V A}$ - virgin aggregate temperature; $S_{R A P}$ - added RAP quantity; $\mathrm{T}_{R A P}-\mathrm{RAP}$ temperature; $W_{R A P}-\mathrm{RAP}$ moisture content,

(2) (Wu et al., 2007):

$$
\ln T_{V A}=\frac{\ln T_{A M}-\left(S_{R A P}^{2}-\frac{1}{122 \cdot S_{R A P}}\right) \cdot \ln T_{R A P}}{1-S_{R A P}^{2}},
$$

where: $T_{V A}$ - virgin aggregate temperature; $S_{R A P}$ - added RAP quantity; $\mathrm{T}_{R A P}-\mathrm{RAP}$ temperature; $T_{A M}-\mathrm{AM}$ temperature,

(3) (Stephanos \& Pagán-Ortiz, 2011):

$$
T_{V A}=\frac{T_{A M}-\left(S_{R A P} \cdot T_{R A P}\right)}{1-S_{R A P}},
$$

where: $T_{V A}$ - virgin aggregate temperature; $T_{A M}-\mathrm{AM}$ temperature; $S_{R A P}-$ added RAP quantity; $\mathrm{T}_{R A P}-\mathrm{RAP}$ temperature,

and (4) (Frederick \& Tario, 2009):

$$
\begin{aligned}
T_{V A}= & \left(\left(-0.0516+0.0143 \cdot W_{R A P}+0.0034 \cdot T_{A M}\right) \cdot S_{R A P}^{2}+\right. \\
& \left(2.1954+0.103 \cdot W_{R A P}+0.0017 \cdot T_{A M}\right) \cdot S_{R A P}+ \\
& \left.2.8 \cdot W_{R A P}+1.063 \cdot T_{A M}-254.124\right)+T_{A M},
\end{aligned}
$$

where: $T_{V A}$ - virgin aggregate temperature; $S_{R A P}$ - added RAP quantity; $T_{A M}$ - AM temperature; $W_{R A P}-\mathrm{RAP}$ moisture content.

Results from plant and theoretical results were compared and listed in Table 3.

Table 3. Some main data of experiment and calculated values

\begin{tabular}{|c|c|c|c|c|c|}
\hline Data type & $\begin{array}{c}\text { Added RAP } \\
\text { quantity, } \%\end{array}$ & $\begin{array}{c}\text { RAP moisture } \\
\text { content, } \%\end{array}$ & $\begin{array}{c}\text { RAP temperature, } \\
{ }^{\circ} \mathrm{C}\end{array}$ & $\begin{array}{c}\text { AM temperature, } \\
{ }^{\circ} \mathrm{C}\end{array}$ & $\begin{array}{c}\text { Virgin aggregates heating } \\
\text { temperature, }{ }^{\circ} \mathrm{C}\end{array}$ \\
\hline Experimental & 20 & 4.8 & 5.3 & 156 & 257 \\
\hline$(1)$ & 20 & 4.8 & 5.3 & 160 & 229 \\
\hline$(2)$ & 20 & not applied & 5.3 & 160 & 213 \\
\hline$(3)$ & 20 & not applied & 5.3 & 160 & 199 \\
\hline$(4)$ & 20 & 4.8 & 5.3 & 160 & 208 \\
\hline
\end{tabular}

Deviations from theoretical virgin material required heating temperature calculations as they are listed in Table 3 , are bellow in 11 to $23 \%$ as in experimental phase while calculated AM temperature is $2.5 \%$ higher. Most probably that theoretical deviations are influenced by process as formulas (2), (3) and (4) were established adding cold RAP to the heating drum where different heat transfer processes (conduction, convection and radiation) are ongoing. Most critical measure - mixing time - which is not calculated theoretically is main factor leading the lower calculated required virgin material temperature.

For the future experiment in MAP equipped with hot RAP addition (parallel drum) would be proceeded as to make other comparison to theoretical calculation background. 


\section{Conclusions}

1. Recycling small quantities and portions of RAP, cold addition to AM method is widely used. Preparation of AMP for this method is simpler as well as less structural design changes.

2. Most flexible is combined RAP addition method as widest range of RAP portions possible to be dosed to AM. In case if RAP is classified into fine and course fractions before addition to AM and applying combined RAP addition method bitumen and fines caking is prevented on parallel drum lifters.

3. Counter-flow with indirect RAP heating method is most environmentally friendly due lowest emissions and energy quantity savings.

4. AMP structural design changes in last 4 decades are slightly changed while RAP recycling technological innovations are driven by authorities' regulations and market demand.

5. Experimental results comparison to theoretical calculations indicates that some correction factors should be taken into theoretically calculating required heating temperature for virgin materials applying cold RAP recycling into the mixer method.

\section{References}

Deutscher Asphaltverband. (2020). Asphaltproduktion in Deutschland 2019 (Stand Januar 2020). https://www.asphalt.de/themen/aktuelles/asphaltproduktion-2019/

Frederick, G., \& Tario, J. D. (2009). Quantify the energy and environmental effects of using recycled asphalt and recycled concrete for pavement construction: Phase I final report. New York State Department of Transportation, Albany, NY.

Gencer, M. N., Gencer, S. E., Karagahin, M., Memis, M., \& Kunduraciodlu, G. (2012, June 13-15). A new method for hot recycling of asphalt. In Proceedings of $5^{\text {th }}$ Eurasphalt \& Eurobitume Congress, Istanbul. https://trid.trb.org/view/1216708

Lithuanian Road Administration. (2009). Automobiliu keliu asfalto mišiniu techniniu reikalavimu aprašas TRA ASFALTAS 08 [Technical requirements of asphalt mixtures used for the road construction TRA ASFALTAS 08].

Martišius, M. (2020). Reclaimed asphalt usage: Handling, processing, management and future trends in Lithuania. Lectures Notes in Civil Engineering, 48, 294-302. https://doi.org/10.1007/978-3-030-29779-4_29

Mogawer, W., Bennert, T., Daniel, J. S., Bonaquist, R., Austerman, A., \& Booshehrian, A. (2012). Performance characteristics of plant produced high RAP mixtures. Road Material and Pavement Design, 13, 183-208. https://doi.org/10.1080/14680629.2012.657070

Nguyen, H. V. (2013). Effects of mixing procedures and rap sizes on stiffness distribution of hot recycled asphalt mixtures. Construction and Building Materials, 74, 728-742 https://doi.org/10.1016/j.conbuildmat.2018.11.239

Puccini, M., Leandri, P., Tasca, A. L., Pistonesi, L., \& Losa, M. (2019). Improving the environmental sustainability of low noise pavements: Comparative life cycle assessment of reclaimed asphalt and crumb rubber based warm mix technologies. Coatings, 9, 343. https://doi.org/10.3390/coatings9050343

Shirodkar, P., Mechta, Y., Nolan, A., Sonpal, K., Norton, A., Tomlison, C., Dubois, E., Sullivan, P., \& Sauber, R. (2011). A study to determine the degree of partial blending of reclaimed asphalt pavements (RAP) binder for high RAP hot mix asphalt. Construction and Building Materials, 25, 150-155. https://doi.org/10.1016/j.conbuildmat.2010.06.045

Sivilevičius, H., Bražiūnas, J., \& Prentkovskis, O. (2017). Technologies and principles of hot recycling and investigation of preheated reclaimed asphalt pavement batching process in asphalt mixing plant. Applied Sciences, 7(11), 1-20. https://doi.org/10.3390/app7111104

Sivilevičius, H., \& Vislavičius, K. (2019). Simulation of composition of recycled hot-mix asphalt mixture produced in asphalt mixing plant. Construction and building Materials, 214, 17-27. https://doi.org/10.1016/j.conbuildmat.2019.03.330

Stephanos, P., \& Pagán-Ortiz, J. E. (2011). Reclaimed asphalt pavement in asphalt mixtures: State of the practice (FHWA-HRT11-021). Research, Development, and Technology Turner-Fairbank Highway Research Center.

Vislavičius, K., \& Sivilevičius, H. (2013). Effect of reclaimed asphalt pavement gradation variation on the homogeneity of recycled hot-mix asphalt. Archives of Civil and Mechanical Engineering, 13(3), 345-353. https://doi.org/10.1016/j.acme.2013.03.003

Zaumanis, M., Boesiger, L., Kunz, B., Cavalli, M. C., \& Poulikakos, L. D. (2019). Determining optimum rejunevator addition location in asphalt production plant. Construction and Building Materials, 198, 368-378. https://doi.org/10.1016/j.conbuildmat.2018.11.239

Zaumanis, M., Cavalli, M. C., \& Poulikakos, L. D. (2020). Effect of rejuvenator addition location in plant on mechanical and chemical properties of RAP binder. International Journal of Pavement Engineering, 21(4), 507-515. https://doi.org/10.1080/10298436.2018.1492133

Zaumanis, M., Mallick, R. B., \& Frank, R. (2014). 100\% recycled hot mix asphalt: A review and analysis. Resources, Conservation and Recycling, 92, 230-245. https://doi.org/10.1016/j.resconrec.2014.07.007

Zhang, K., Huchet, F., \& Hobbs, A. (2019). A review of thermal processes in the production and their influences on performance of asphalt mixtures with reclaimed asphalt pavement (RAP). Construction and Building Materials, 206, 609-619. https://doi.org/10.1016/j.conbuildmat.2019.02.057

Wu, S., Qiu, J., Mo, L., Yu, J., Zhang, Y., \& Li, B. (2007). Investigation of temperature characteristics of recycled hot mix asphalt mixtures. Resources, Conservation and Recycling, 51, 610-620. https://doi.org/10.1016/j.resconrec.2006.11.005 